\title{
Colon Intramucosal Adenocarcinoma
}

National Cancer Institute

\section{Source}

National Cancer Institute. Colon Intramucosal Adenocarcinoma. NCI Thesaurus. Code C45429.

An adenocarcinoma that arises from the colonic glandular epithelium and invades the lamina propria or muscularis mucosa but not the submucosa. 